\title{
Para além dos preços contratados: fatores determinantes da celeridade nas entregas de compras públicas eletrônicas
}

\author{
Paulo Ricardo da Costa Reis \\ Universidade Federal do Rio de Janeiro / Instituto de Pesquisa e Planejamento Urbano e Regional \\ Rio de Janeiro / RJ — Brasil \\ Universidade Federal Rural do Rio de Janeiro / Programa de Pós-Graduação em Gestão e Estratégia \\ Seropédica / RJ - Brasil \\ Universidade Federal da Bahia / Núcleo de Pós-Graduação em Administração \\ Salvador / BA — Brasil
}

\section{Sandro Cabral}

Insper Instituto de Ensino e Pesquisa

São Paulo / SP — Brasil

Universidade Federal da Bahia / Núcleo de Pós-Graduação em Administração (licenciado)

Salvador / BA - Brasil

Estudos sobre a efetividade das compras públicas frequentemente enfatizam o preço de aquisição. Pouco se sabe, contudo, sobre outras dimensões de desempenho das contratações realizadas pelo governo, incluindo as relações de interdependência entre custo de aquisição e qualidade. Usando a celeridade na entrega como dimensão alternativa de desempenho, este estudo investigou quais são os mecanismos que ajudam a compreender a redução dos preços contratados e dos prazos de entrega dos objetos adquiridos por meio de compras públicas eletrônicas, bem como a influência da economia obtida na fase de licitação sobre a celeridade da entrega. Analisando uma base de dados única, com informações detalhadas de 3.755 processos de compras realizadas por um órgão do governo federal, constatou-se que, embora as licitações eletrônicas sejam eficazes para reduzir preços contratados nos certames de intensa competição, não há relação significativa entre o acirramento da concorrência entre os participantes e a celeridade na entrega. Ademais, os resultados indicam que fornecedores com histórico de desempenho insatisfatório são exatamente aqueles que continuam comprometendo o resultado das compras públicas.

Palavras-chave: licitações eletrônicas; competição; prazo de entrega.

\section{Más allá de los precios contratados: factores determinantes para la rapidez en las entregas de compras públicas electrónicas}

Estudios sobre la efectividad de las compras públicas frecuentemente enfatizan sobre el precio de adquisición. Sin embargo, se sabe poco sobre otras dimensiones de desempeño de las contrataciones realizadas por los gobiernos. Usando la rapidez en la entrega como una segunda dimensión de desempeño, este estudio investigó cuáles son los mecanismos que ayudan a comprender la reducción de los precios contratados y de los plazos de entrega de los objetos adquiridos en un portal electrónico de compras públicas, así como la influencia del ahorro obtenido en la fase de licitación sobre la rapidez en la entrega. Analizando una base de datos única, con informaciones detalladas de 3.755 procesos de compras realizadas por un órgano del gobierno federal, se comprobó que, aun cuando las licitaciones electrónicas sean eficaces para reducir los precios contratados en concursos de intensa competición, no existe una relación significativa entre la agresiva competencia entre los participantes y la rapidez en la entrega. Además, los resultados indican que proveedores con histórico de desempeño insatisfactorio son exactamente aquellos que continúan comprometiendo el resultado de las compras públicas.

Palabras-clave: licitaciones electrónicas; competencia; plazo de entrega. 


\section{Beyond contracted prices: determinants of agility in government electronic procurement}

Studies on the effectiveness of government procurement have a prominent focus on contracted prices. However, not much is known about other dimensions of the performance of contracts awarded by the government such as the relation of interdependence between contracted prices and quality. Using delivery time as a dimension for quality, this study explores the mechanisms that influence contracted prices and delivery time. It also discusses how price reduction influences ex-post quality in the context of government electronic procurement. Analysis using a data base with detailed information of 3,755 procurement processes executed by a Brazilian organization of the Federal Public Administration shows that, despite procurement processes being effective to reduce prices in competitive bids, there is no evidence that this price reduction negatively affects delivery time. In addition, results show that suppliers with a history of poor performance are those that keep harming government procurement performance.

Keywords: electronic procurement; bidding; competition; delivery time.

\section{INTRODUÇÃO}

Organizações públicas têm sido cada vez mais pressionadas para melhorar seu desempenho na prestação de serviços, em meio a um cenário de crescentes restrições fiscais (Gill e Frame, 1990; Boyne e Walker, 2010). A necessidade de responder a essas pressões tem levado as organizações governamentais a adotar medidas internas para melhorar seu desempenho. Tais medidas atingem diversas áreas, entre as quais compras públicas (Kelman, 2002; Moon, 2002). Isso significa que as organizações públicas estão cada vez mais propensas a implementar ferramentas que possam garantir a boa governança em seus processos de contratação, por exemplo, com as plataformas online de compras. Tais ferramentas têm sido largamente utilizadas por diversos governos ao redor do globo, sobretudo em função de permitirem a automatização do processo de licitação, contribuírem para a redução dos custos de contratação, para o aumento da celeridade no processo licitatório e a ampliação da transparência nos gastos públicos (Moon, 2005; Unpan, 2011).

Todavia, embora exista uma crescente literatura focalizada na implementação das plataformas eletrônicas de compras públicas (Moon, 2005; Fernandes, 2005; Menezes, Silva e Linhares, 2007; Doherty, McConnell e Ellis-Chadwick, 2013) e em seus impactos em termos de simplificação do processo de licitação e redução dos preços contratados (Croom e Brandon-Jones, 2007; Faria et al., 2010b), as implicações das licitações eletrônicas sobre o comportamento dos licitantes e os indicadores de desempenho ex post das compras públicas ainda permanecem pouco explorados (Freitas e Maldonado, 2013; Reis e Cabral, 2015). De fato, conforme assinala Tridapalli, Fernandez e Machado (2011), em que pese o potencial financeiro das compras eletrônicas, é necessário ampliar a discussão para uma visão mais ampla de gestão da cadeia de suprimento, pois não são raros os registros de desvios noticiados pela imprensa brasileira e indicados pelas auditorias dos órgãos fiscalizadores nas aquisições eletrônicas realizadas pelo governo. Destarte, no presente trabalho, procura-se responder à seguinte pergunta de pesquisa: quais são os mecanismos que ajudam a compreender a redução dos preços contratados e dos prazos de entrega dos objetos licitados em um portal eletrônico de compras públicas?

Para responder essa questão, recorreu-se ao exame de uma base de dados única, contendo informações de 3.755 lotes padronizados de compras adquiridos por uma organização da administração pública federal (APF) brasileira, por meio de licitações eletrônicas realizadas nos anos de 2013 e 2014. Utilizando regressões múltiplas e tendo como variáveis de desempenho a redução no preço 
contratado e a celeridade na entrega dos itens adquiridos, os resultados do estudo mostram que, embora os avanços proporcionados pelas licitações eletrônicas tenham sido eficazes ao aumentar a economia para o erário público em certames de maior competição, não foi possível identificar uma associação entre a redução nos preços licitados e a celeridade na entrega. Porém, em consonância com o desenvolvimento teórico realizado, outro fator examinado no estudo chama a atenção: fornecedores com histórico de desempenho insatisfatório são justamente aqueles que permanecem deteriorando os resultados das compras públicas nos quesitos preço e prazo. Em verdade, a reputação, mecanismo largamente utilizado para prevenir o oportunismo ex post (Standifird, 2001; Spagnolo, 2012), não parece ser eficaz no contexto brasileiro de compras públicas.

Além desta introdução, o estudo está organizado em mais sete seções. Na segunda seção, são apresentados o referencial teórico e as hipóteses abordadas na pesquisa. Na terceira, destaca-se o contexto institucional das licitações eletrônicas no Brasil. Na quarta, são apresentados os procedimentos metodológicos que nortearam a realização da pesquisa. A quinta e a sexta seções exibem a análise e a discussão dos resultados. A última seção destaca as considerações finais, limitações e implicações da pesquisa.

\section{TEORIA E HIPÓTESES}

Diante do impacto das tecnologias da informação e comunicação (TICs) sobre o funcionamento das organizações, muitos países têm se engajado ativamente em investimentos voltados a explorar as potencialidades apresentadas pelos sistemas eletrônicos de compras públicas (Unpan, 2011). Entre os investimentos comumente realizados, destaca-se o desenvolvimento de plataformas online para realização de licitações eletrônicas. Tais plataformas, sem dúvida, representam uma das principais aplicações das TICs na gestão de cadeia de suprimentos no setor público (Moon, 2002; Tridapalli, Fernandez e Machado, 2011). As licitações eletrônicas caracterizam-se pela realização de todas as etapas do processo de contratação em um ambiente online, possibilitando a comunicação e a interação à distância entre os agentes públicos responsáveis pela licitação e as organizações privadas interessadas em fornecer bens ou serviços para a administração pública.

Os benefícios esperados com a implantação de plataformas online de compras têm sido bem documentados na literatura e incluem resultados financeiros, como a redução nos preços contratados e nos custos de aquisição (Moon, 2002; Unpan, 2011); operacionais, como a celeridade do processo de adjudicação, a padronização e a racionalização dos procedimentos de aquisição e a melhoria do fluxo de comunicação entre governo, fornecedores e sociedade (Croom e Brandon-Jones, 2007); e estratégicos, por meio da ampliação das fontes de fornecimento e da melhoria na transparência, facilitando o acompanhamento das contratações realizadas pelas organizações públicas e reduzindo o potencial de corrupção (Reis e Cabral, 2015).

Contudo, o uso das licitações eletrônicas é recomendado apenas nas aquisições de bens e serviços comuns, ou seja, bens e serviços com baixa complexidade e que podem ser completamente especificados ex ante (Yukins e Wallace Jr., 2005); e nas situações em que existe um número razoável de fornecedores para o objeto ou serviço demandado (Caniëls e Van Raaij, 2009). Ademais, mesmo para contratações de baixa especificidade, o uso das plataformas eletrônicas suscita discussões. Brandon-Jones e Carey (2011) argumentam que muitas organizações não alcançaram os resultados pretendidos com a aplicação dos sistemas eletrônicos de contratação. Umas das principais críticas, 
particularmente no setor privado, é que o uso das compras eletrônicas vai de encontro a uma consolidada e crescente literatura na área de gestão de cadeias de suprimentos que evidencia os benefícios do desenvolvimento de relações de parcerias e confiança entre fornecedor e comprador (Tassabehji et al., 2006), bem como o papel dos trade-offs logísticos em políticas públicas (Vaz e Lotta, 2011).

Igualmente, um número pequeno, porém crescente, de estudos tem questionado os impactos das licitações eletrônicas sobre o comportamento dos fornecedores (Caniëls e Van Raaij, 2009; Freitas e Maldonado, 2013). Os críticos argumentam que o forte apelo para o valor do dinheiro e para a rivalidade entre os licitantes nas compras eletrônicas pode estimular a ocorrência de comportamentos oportunistas entre os fornecedores (Jap, 2007), que podem adotar estratégias autointeressadas em relação aos prazos e padrões de qualidade dos bens e serviços especificados no edital, como forma de recuperar as perdas incorridas durante a disputa de preços (Faria et al., 2010a).

Ademais, na medida em que as licitações eletrônicas são utilizadas para reduzir as barreiras à entrada e estimular comportamentos mais agressivos dos fornecedores na disputa dos lances, tais licitações poderiam atrair fornecedores menos eficientes e, logo, mais propensos a comprometerem a execução do contrato, particularmente nas aquisições com mecanismos insuficientes de pré-qualificação dos licitantes ou especificações imprecisas (Tassabehji et al., 2006). Como resultado, existe um risco potencial de que as contratações eletrônicas impliquem custos adicionais ex post que podem, até mesmo, ser superiores à economia obtida ex ante. Todavia, embora uma parcela da literatura demonstre apreensão quanto à consolidação de muitos dos resultados esperados com o uso das licitações eletrônicas, esse mecanismo de contratação é uma ferramenta consolidada e que faz parte da realidade dos governos (Unpan, 2011), naturalmente requerendo ajustes para seu apropriado funcionamento.

Na sequência, discorre-se sobre os diversos fatores que podem influenciar o desempenho das aquisições eletrônicas, explorando o papel do ambiente competitivo (Bulow e Klemperer, 1996), o papel das competências acumuladas (Teece, Pisano e Shuen, 1997) e o da reputação sobre o desempenho de uma contratação (Spagnolo, 2012).

\subsection{AMBIENTE COMPETITIVO}

As teorias ligadas à área de compras asseguram que o estabelecimento de condições favoráveis à entrada de novos participantes nas licitações aumenta a concorrência entre os fornecedores, resultando em uma maior redução nos preços contratados (Bulow e Klemperer, 1996). Nesse sentido, considerando ativos de especificidade relativamente baixa e a capacidade das plataformas online de compras públicas para reduzir as barreiras à entrada e simplificar o processo de aquisição - o que permite a redução dos custos de participação para fornecedores geograficamente dispersos -, admite-se que as aquisições online contribuem para um aumento no número de fornecedores competindo pelo objeto licitado. Tal incremento no número de participantes pode ser traduzido em ganhos para a organização compradora em termos de preços contratados. Portanto, espera-se uma associação positiva entre o número de licitantes e a economia obtida nas compras eletrônicas. Formalmente:

H1: Quanto maior o número de concorrentes nas licitações públicas eletrônicas, maior a economia nos preços praticados.

Todavia, embora a literatura enfatize a importância da variável preço como medida de desempenho das compras públicas, é consenso que a economia obtida na licitação só adquire relevância quando ela é qualificada por outras dimensões de desempenho que incluem, por exemplo, a tempestividade 
e a qualidade da entrega (Ba e Pavlou, 2002; Vaz e Lotta, 2011). Isso significa que uma aquisição com desempenho satisfatório vai muito além da redução no preço, sendo igualmente necessário evitar os custos de adaptação ex post, garantindo que sua entrega seja realizada no prazo e com as especificações estabelecidas no edital de forma a garantir a satisfação dos usuários dos bens e serviços adquiridos.

Dessa forma, um problema potencial das licitações eletrônicas decorre exatamente do sucesso desse mecanismo de contratação, revelado em preços licitados potencialmente inexequíveis. Isso porque a ênfase sobre a redução nos preços durante o certame pode produzir uma seleção adversa, inibindo a participação de fornecedores mais capacitados que pretendem competir em qualidade e tempestividade (em vez de preço) (Caniëls e Van Raaij, 2009), principalmente nas aquisições com mecanismos de pré-qualificação de fornecedores e especificações insuficientes (Tassabehji et al., 2006). Adicionalmente, os fornecedores também podem sentir a necessidade de reduzir os níveis de qualidade dos objetos e serviços ofertados para suportar a queda nas suas margens e tornarem-se mais competitivos na disputa por menor preço (Jap, 2002).

No contexto brasileiro, estudos anteriores, como os realizados por Freitas e Maldonado (2013), alertam que não é incomum que uma empresa seja contratada numa licitação eletrônica ofertando um preço muito abaixo do praticado no mercado, e que essa empresa não seja capaz de cumprir sua oferta. Este processo de subprecificação poderia ser explicado tanto pela inexperiência do licitante que se deixa levar pelo acirramento do clima de disputa na concorrência como pela ação deliberada do fornecedor para evitar a perda do contrato. Nesse último caso, os fornecedores poderiam reduzir seus preços com base na expectativa de um reajuste ex post ou simplesmente na entrega de um produto ou serviço de menor qualidade, com especificações que não atendam ao edital. Assim, dado que comportamentos oportunistas parecem ser factíveis em licitações públicas eletrônicas, suspeita-se que a economia obtida na fase de lances possa ser transitória (Tassabehji et al., 2006), numa clara manifestação de trade-offs logísticos entre custo, qualidade, velocidade e externalidades positivas ou negativas (Hart, Shleifer e Vishny, 1997; Vaz e Lotta, 2011). Logo:

H2: Quanto maior a economia obtida na licitação eletrônica, maior a dilatação no prazo de entrega do objeto contratado.

\subsection{CAPACIDADES ACUMULADAS}

Capacidade ou competência organizacional é um conceito estabelecido pela literatura de estratégia (Teece, Pisano e Shuen, 1997), porém recentemente mobilizadas pela área de administração pública (Piening, 2013; Cabral, 2017). Tais dimensões apontam para a importância da combinação de um conjunto de recursos tangíveis e intangíveis que permite às organizações competirem no mercado em condições de obter um desempenho superior (Barney, 1991). Para Winter (2003), a capacidade organizacional refere-se, essencialmente, ao conjunto de processos internos, rotinas e habilidades que uma organização desenvolve para gerenciar sua atividade finalística com eficiência e diferenciar-se dos seus concorrentes.

Em relação ao desenvolvimento de competências organizacionais, é preciso destacar a dificuldade para se estabelecer quais são as ações que uma organização deve adotar para construir uma competência que efetivamente proporcione um desempenho superior. Todavia, Teece, Pisano e Shuen (1997) reconhecem que o conhecimento e a experiência acumulada pelas organizações são meios importantes para o desenvolvimento de capacidades e competências. Segundo Barney (1999), em 
alguns casos, para desenvolver uma competência, a organização precisa passar por um intenso e longo processo de aprendizagem, pois são as experiências acumuladas ao longo de sua história que possibilitam o aprendizado de novas práticas e rotinas que podem estabelecer capacidades organizacionais. Portanto, a aprendizagem é um processo que combina experimentação e repetição com o propósito de melhorar continuamente o desempenho organizacional (Eisenhardt e Martin, 2000).

Assim, espera-se que o aprendizado obtido pelas organizações, ao longo do tempo, funcione como fator que impulsiona a geração de valor nas aquisições públicas eletrônicas (Cabral, 2017). Como resultado, pode-se sugerir que os fornecedores mais experientes tenham acumulado um estoque de capacidades potencialmente mais valiosas e, por isso, sejam capazes de ofertar um produto ou serviço que atenda as especificações estabelecidas no edital de licitação, com preços mais baixos que os concorrentes menos experientes, ou com especificações e execução superiores, ao mesmo preço dos concorrentes. Portanto:

H3: Quanto maior a competência acumulada pela empresa contratada, maior a economia nos preços praticados.

H4: Quanto maior a competência acumulada pela empresa contratada, menor o prazo de entrega do objeto contratado.

\subsection{REPUTAÇÃO}

Embora se reconheça que o acirramento da competição possa estimular a ocorrência de comportamentos oportunistas nas relações contratuais, diversos estudos na área de contratação demonstraram que esses comportamentos podem ser evitados com o uso de termos contratuais que reforcem o desejo de construir uma reputação ou a intenção de premiar uma atitude anterior (Barney e Hansen, 1994). Mesmo nas contratações de produtos de baixa complexidade, em que a qualidade e os prazos de entrega podem ser facilmente especificados, pesquisadores e especialistas da área reconhecem a reputação como um elemento crucial para a redução dos custos de transação e o aumento da eficiência, nas relações cliente-fornecedor, sobretudo em um contexto de interações repetidas e assimetria de informação (Spagnolo, 2012).

A reputação de um fornecedor representa a avaliação atual da sua capacidade para cumprimento do contrato com um resultado satisfatório. Tal avaliação é estabelecida com base no histórico de desempenho desse fornecedor na própria organização contratante ou a partir de informações de terceiros. Para Barney e Hansen (1994), a importância de se construir uma reputação positiva deriva, em parte, da incapacidade do fornecedor para manipular sua própria reputação. Assim, o risco de perdas decorrentes de uma reputação danificada por condutas oportunistas em transações passadas, somado à incapacidade do fornecedor para manipular sua própria reputação, cria condições favoráveis para que um fornecedor com elevada reputação continue agindo de forma responsável e confiável nas transações atuais e futuras, dado que seu comportamento terá consequências sobre sua reputação (Standifird, 2001; Ba e Pavlou, 2002). Dessa perspectiva, nota-se que mecanismos de incentivos baseados em reputação têm sido largamente utilizados em plataformas online de compras envolvendo agentes privados, como nos casos de feedback dos usuários da Amazon, eBay e Freelancer.com.

No setor público, embora uma literatura recente ressalte a importância do histórico de desempenho como uma medida da reputação a ser utilizada nas compras públicas, dado que várias contratações semelhantes são realizadas ao longo do ano (Spagnolo, 2012), ainda são raras as experiências que em- 
pregam mecanismos de reputação para melhoria das compras eletrônicas. Ademais, vale lembrar que, na ausência de mecanismos que permitam a punição de fornecedores com histórico de desempenho insatisfatório ou a premiação de fornecedores com bom desempenho, a construção e a manutenção de uma reputação confiável não parecem algo factível. Assim, considerando que o regulamento de compras públicas brasileiro não permite o uso desse tipo de mecanismo nas licitações eletrônicas, pode-se supor que os fornecedores com histórico de desempenho insatisfatório serão justamente aqueles que apresentarão problemas na execução do contrato. Logo:

H5: Quanto maior o histórico de desempenho insatisfatório de um fornecedor, maior o prazo de entrega do objeto contratado.

\section{LICITAÇÕES ELETRÔNICAS NO BRASIL}

No Brasil, as licitações públicas eletrônicas foram instituídas no início dos anos 2000 por meio da modalidade de licitação denominada pregão, que é destinada exclusivamente para aquisição de bens e serviços comuns no mercado, independentemente do valor a ser adquirido, adotando obrigatoriamente o critério de "menor preço" para seleção do fornecedor. Na sua forma eletrônica, todo o processo de contratação na modalidade pregão é conduzido pela internet, sendo a disputa por lances realizada em uma sala virtual com sistema proprietário da autoridade pública. O Portal de Compras do Governo Federal (Comprasnet) é a principal plataforma utilizada para operar os processos eletrônicos de aquisições e disponibilizar informações referentes aos editais e às atas de licitações e contratações realizadas pelos órgãos do governo federal. Todos os dias, cerca de 400 licitações são feitas no Comprasnet (Brasil, 2015).

Ao instituir a modalidade pregão, na forma eletrônica, o governo buscava incrementar a competitividade e a agilidade nas contratações públicas, explorando as vantagens proporcionadas pela internet. Entre as inovações introduzidas pelas licitações eletrônicas, vale destacar a permissão para sua utilização nos procedimentos de contratação por meio do sistema de registro de preços (SRP). Esse sistema, comparativamente às contratações convencionais, tem como principal característica a não obrigatoriedade de efetivar a aquisição do objeto ou serviço licitado. Nas modalidades que não utilizam o SRP, a licitação destina-se a selecionar o fornecedor e a proposta para uma contratação específica, efetivada pelo gestor público ao final do procedimento licitatório. No SRP, por sua vez, a licitação tem como finalidade selecionar o fornecedor, com menor preço, para eventuais contratações futuras. Assim, após realização da licitação, preços e condições de aquisição ficam gravados na ata de registro de preços, por um período de até 12 meses, cabendo ao gestor público recorrer a essa ata quando julgar necessário.

Quanto à aplicabilidade, o SRP deverá ser adotado preferencialmente quando: em função das características do objeto ou serviço houver necessidade de contratações frequentes; não for possível definir previamente o quantitativo demandado; for mais conveniente a aquisição de bens com previsão de entregas parceladas; e for vantajosa a aquisição de bens ou a contratação de serviços para atendimento a mais de um órgão ou a programas de governo. Dessa forma, admitindo que a grande maioria das atividades desenvolvidas pelos órgãos públicos envolve contratações de bens e serviços de uso frequentes e com entregas parceladas, nota-se um crescimento no uso das licitações eletrônicas SRP nos últimos cinco anos (figura 1). Nesse período, 98,8\% dos pregões realizados pelo governo federal foram eletrônicos, e as licitações SRP representaram 40,2\% do 
valor total licitado, em 2010. Nesse mesmo ano, a modalidade pregão para contratação específica representou apenas 9,1\% do valor total licitado. Apesar de uma queda em 2011, a participação do SRP nos valores licitados apresentou uma tendência de crescimento entre 2011 e 2014, enquanto os valores licitados, por meio da modalidade pregão para contratação específica, mantiveram uma tendência constante ao longo de todo o período analisado (10,6\%). Em 2014, o SRP totalizou 60,2\% do montante licitado pelo governo federal.

FIGURA 1 PERCENTUAL DOS VALORES LICITADOS POR PREGÃO ELETRÔNICO PARA CONTRATAÇÃO ESPECÍFICA (SISPP) E SRP NO MONTANTE LICITADO PELA APF

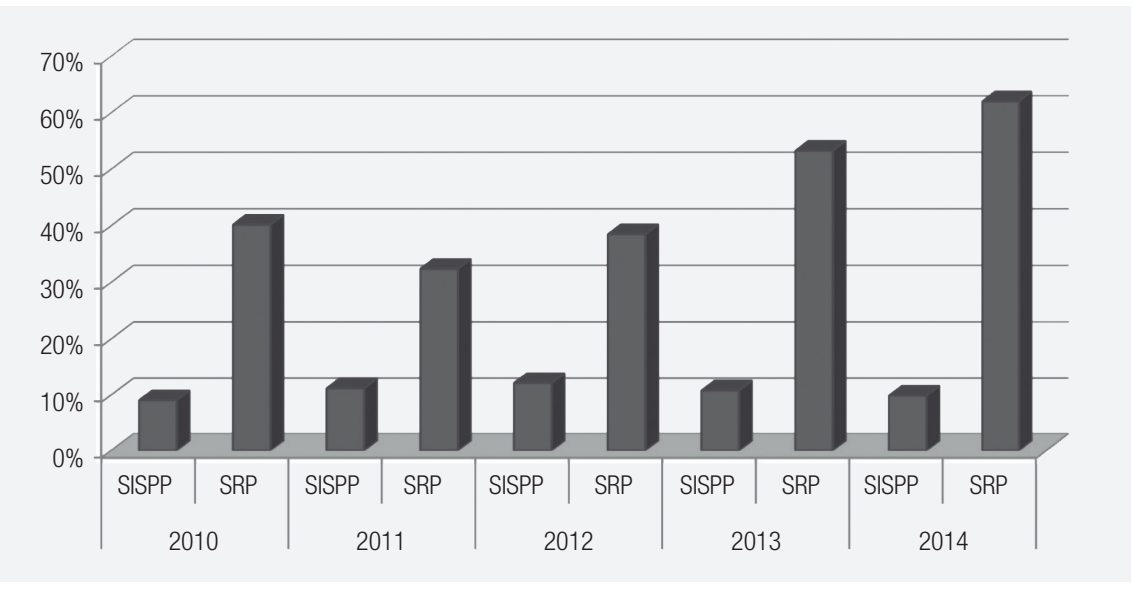

Fonte: Brasil (2015).

\section{PROCEDIMENTOS METODOLÓGICOS}

Os dados utilizados na pesquisa incluem informações de 3.755 lotes padronizados de compras, licitados por meio da modalidade pregão eletrônico (SRP) por um órgão da APF ligado ao Ministério da Educação (Organização X), nos anos de 2013 e 2014. A unidade de análise utilizada é o lote de compra que é a unidade mínima de transação no contexto avaliado. Cada pregão é composto por um ou mais lotes de compras e cada lote é composto por um único tipo de objeto.

Quanto à escolha da Organização X para concretização da pesquisa, deve-se ressaltar a dificuldade envolvida na coleta de dados sobre os indicadores de desempenho de compras públicas no Brasil. Apesar dos avanços proporcionados pelas plataformas online de compras, a transparência sobre os eventos que ocorrem após a seleção do fornecedor ainda é demasiadamente limitada. Nesse sentido, diante da ausência de registros públicos sistematizados e disponíveis eletronicamente para consulta, o levantamento de dados sobre o desempenho ex post das contratações somente foi possível por meio de uma pesquisa documental in loco e on-site direcionada às notas fiscais de compra arquivadas em diferentes unidades da organização pesquisada.

Além das notas fiscais, o presente estudo utilizou cinco diferentes fontes de dados para realização da pesquisa documental: Comprasnet, Sistema de Cadastramento Unificado de Fornecedores (Sicaf), Receita Federal (RF), Sistema Integrado de Patrimônio, Administração e Contratos (Sipac) 
e Portal da Transparência (PT). No Comprasnet, utilizando as atas dos pregões, foram coletadas as informações referentes à especificação do lote licitado, o valor estimado para o lote, o desfecho da licitação (adjudicado, revogado ou deserto), o valor do lance contratado e o número do Cadastro Nacional de Pessoa Jurídica (CNPJ) da empresa vencedora. No Sicaf, foram pesquisadas informações sobre a data de cadastramento da empresa contratada no Sistema e o histórico de sanções recebidas pela empresa. $\mathrm{Na} \mathrm{RF}$, foram recolhidas informações sobre idade, localização e porte da empresa vencedora. No Sipac, foram obtidas informações sobre a data de entrada dos objetos no Almoxarifado Central da Organização X, entre janeiro de 2014 e setembro 2015, e o número da nota de empenho com a requisição desses objetos. As informações coletadas no Sipac complementam os dados obtidos nas notas fiscais, que foram coletados por meio da pesquisa in loco em diferentes unidades da Organização X. Por fim, no PT, foram coletadas todas as notas de empenho emitidas pela Organização X, em 2014 e 2015, para requisição de material de consumo.

\subsection{VARIÁVEIS DE DESEMPENHO}

O estudo utilizou duas variáveis dependentes. A primeira variável "Redução nos preços" mensura a variação nos preços contratados comparativamente aos valores estimados previamente para aquisição. A escolha dessa variável justifica-se na medida em que a preocupação em relação ao uso dos recursos do contribuinte e a busca pelo melhor preço nas compras gorvernamentais são algumas das principais razões para a realização das licitações públicas (Bajari, McMillan e Tadelis, 2009). A segunda variável refere-se à celeridade da entrega, que é um objetivo importante da função de compras, dado que em aquisições eletrônicas o atraso injustificável na entrega é uma das formas mais comuns dos comportamentos oportunistas adotados pelos fornecedores (Ba e Pavlou, 2002). A variável "Prazo de entrega" corresponde ao número de dias decorridos entre a emissão da nota de empenho, com a requisição do objeto contratado, até sua entrega na organização.

\subsection{VARIÁVEIS EXPLICATIVAS}

As hipóteses do estudo foram testadas por meio de cinco variáveis. Os efeitos do ambiente competitivo foram analisados através das variáveis "Fornecedores" e "Redução nos preços". A primeira variável indica o número de fornecedores que participaram do certame. Com essa variável pretende-se capturar o efeito da concorrência entre os licitantes sobre desempenho da aquisição em termos de redução nos preços. A variável "Redução nos preços", já definida, também foi utilizada para verificar em que medida a economia alcançada na fase de licitação pode influenciar o desempenho ex post da aquisição, em termos de prazo de entrega. Os efeitos das capacidades acumuladas pelo fornecedor, por sua vez, foram avaliados com base nas variáveis "Experiência no mercado" e "Experiência no setor público". A primeira variável representa o número de anos em que a empresa contratada atua no mercado desde sua criação. A segunda indica há quantos anos a empresa está registrada no Sicaf. Por fim, o efeito da reputação foi analisado com a variável "Histórico de sanção". Essa variável indica o número de sanções que o fornecedor recebeu em contratações anteriores com a organização pesquisada. 


\subsection{VARIÁVEIS DE CONTROLE}

O estudo também utilizou um conjunto de variáveis de controle que podem influenciar as dimensões de desempenho das aquisições eletrônicas. Uma variável relacionada com o tamanho do lote licitado, mensurada pelo "Valor estimado" para aquisição de cada lote, duas variáveis relacionadas com o porte da empresa contratada (dummy igual a 1 se micro e pequena empresa - MPE - foram contratadas) e à "Distância" geográfica entre a empresa contratada e a contratante (em quilômetros). Também foram consideradas outras sete variáveis dummies que caracterizam os objetos contratados (Material de expediente - baseline, Material de limpeza e higienização, Material do gênero alimentício, Material de copa e cozinha, Material de proteção e segurança, Material elétrico e Outros materiais).

\subsection{MODELOS ESTATÍSTICOS}

Do ponto de vista da análise estatística empreendida, considerando-se as características das variáveis de desempenho investigadas, foram utilizados dois diferentes modelos de regressão. Primeiramente, adotou-se um modelo de regressão por mínimos quadrados ordinários (MQO), que tem sido extensamente utilizado nas pesquisas sobre compras públicas (Bajari, McMillan e Tadelis, 2009). Contudo, considerando que as estimativas desse modelo são sensíveis à presença de outliers e sua aplicação exige uma rigorosa verificação de premissas e ajustes para que as estimativas sejam válidas (Wooldridge, 2006), como forma de complementar os resultados obtidos, utilizou-se o modelo de regressão quantílica.

Diferentemente da técnica por MQO, a regressão quantílica permite a análise do impacto de variáveis explicativas em diferentes pontos da distribuição condicional da variável dependente (quantis). Assim, usando a regressão quantílica, foi possível capturar os níveis de sensibilidade das variáveis dependentes para estratos diferentes do conjunto de dados utilizados, facilitando, por exemplo, a análise dos resultados para lotes em pontos extremos da amostra, em termos de "Redução nos preços" e "Prazos de entrega". Para realização da regressão quantílica, a base foi dividida por quartis, de modo que os lotes que obtiveram menor redução nos preços contratados e menores prazos de entrega (q25) se encontram no primeiro quartil (q25 - referente aos 25\% dos lotes com menor economia e menor prazo) e os que alcançaram maior redução e maior prazo estão situados no terceiro quartil (q75). Embora esta técnica seja menos difundida no campo da administração pública, ela pode ser vista como uma extensão do MQO, com a vantagem de permitir uma análise mais apurada, devido, inclusive, à sua robustez quanto à maioria dos inconvenientes observados nos modelos por MQO (Bretschneider, Marc-Aurele Jr. e Wu, 2005).

\section{RESULTADOS E DISCUSSÃO}

A tabela 1 apresenta as estatísticas descritivas das variáveis utilizadas no estudo. A amostra pesquisada é composta 3.755 lotes padronizados de compras, dos quais apenas $88,4 \%$ (3.321) foram adjudicados para um fornecedor. Entre os lotes não adjudicados, aproximadamente $65,2 \%$ dos casos de insucesso estavam relacionados com preços acima do estimado, e 16,8\% ocorreram em função da ausência de fornecedores interessados em participar da concorrência.

Entre os contratos adjudicados, verifica-se uma elevada heterogeneidade na economia obtida nos processos licitatórios e nos prazos de entrega dos objetos adquiridos. Surpreendentemente, uma 
aquisição de material para laboratório com preço unitário estimado em $\mathrm{R} \$ 0,11$ foi realizada por $\mathrm{R} \$ 0,49$, o que representou uma perda para os cofres públicos de $345,45 \%$ em relação ao valor previsto na fase de planejamento. No outro extremo, constatou-se uma aquisição de material químico com preço unitário estimado em $R \$ 25,05$, mas com preço de adjudicação igual a $R \$ 0,05$, o que equivale a uma redução de $99,8 \%$ em relação ao valor estimado. Apesar da amplitude, a economia média observada na amostra foi de $22,2 \%$, o que se aproxima da média nacional nos últimos sete anos, que oscilou entre 18\% e 24\% (Brasil, 2015). Em termos de prazo de entrega, observa-se que o tempo de espera entre a requisição do material e seu recebimento foi, em média, de 28 dias. Esse resultado, $a$ priori, deve ser interpretado com reservas, dado que, em geral, os editais de licitação estabelecem um prazo de entrega de 15 a 30 dias após o recebimento da nota de empenho. Além disso, vale ressaltar que $31,1 \%$ das entregas pesquisadas foram realizadas com um prazo superior a 30 dias.

\section{TABELA 1 ESTATÍSTICAS DESCRITIVAS}

\begin{tabular}{|c|c|c|c|c|c|}
\hline Variáveis & $\mathrm{N}$ & Média & Desvio-Padrão & Mínimo & Máximo \\
\hline \multicolumn{6}{|l|}{ Dependentes } \\
\hline Redução nos preços & 3.321 & 22,20 & 26,07 & $-345,45$ & 99,80 \\
\hline Prazo de entrega & 283 & 27,55 & 13,80 & 1,00 & 66,00 \\
\hline \multicolumn{6}{|l|}{ Explicativas } \\
\hline Fornecedores & 3.755 & 5,83 & 4,42 & 0,00 & 41,00 \\
\hline $\begin{array}{l}\text { Experiência de } \\
\text { mercado (anos) }\end{array}$ & 3.321 & 11,06 & 8,40 & 0,13 & 48,45 \\
\hline $\begin{array}{l}\text { Experiência no setor } \\
\text { público (anos) }\end{array}$ & 3.321 & 6,24 & 4,30 & 0,05 & 18,99 \\
\hline Histórico de sanção & 3.321 & 1,14 & 1,97 & 0,00 & 10,00 \\
\hline \multicolumn{6}{|l|}{ Controles } \\
\hline MPE & 3.321 & 0,80 & 0,40 & 0,00 & 1,00 \\
\hline Distância (km) & 3.321 & $1.038,37$ & $1.029,48$ & 5,60 & 3247,00 \\
\hline Valor estimado (R\$) & 3.755 & $38.017,14$ & $279.854,00$ & 3,80 & 5625000,00 \\
\hline \multicolumn{6}{|l|}{ Tipos de material } \\
\hline $\begin{array}{l}\text { Expediente - } \\
\text { baseline }\end{array}$ & 3.755 & 0,26 & 0,44 & 0,00 & 1,00 \\
\hline \multicolumn{5}{|l|}{ higienização } & 1,00 \\
\hline Gênero alimentício & 3.755 & 0,23 & 0,42 & 0,00 & 1,00 \\
\hline Copa e cozinha & 3.755 & 0,05 & 0,21 & 0,00 & 1,00 \\
\hline Proteção e segurança & 3.755 & 0,04 & 0,21 & 0,00 & 1,00 \\
\hline Elétrico & 3.755 & 0,03 & 0,16 & 0,00 & 1,00 \\
\hline Outros & 3.755 & 0,33 & 0,47 & 0,00 & 1,00 \\
\hline
\end{tabular}

Fonte: Resultados da pesquisa. 
No tocante à variável "Prazo de entrega", cumpre ressaltar que na pesquisa documental realizada nos relatórios de entrada do Almoxarifado Central e nas notas fiscais de compras foi possível identificar a data de entrada para apenas 325 lotes, o que corresponde a, aproximadamente, 10\% dos lotes licitados na amostra pesquisada. Contudo, considerando que a maioria dos empenhos emitidos no mês de novembro é realizada com a finalidade exclusiva de evitar a devolução de recursos para o Tesouro Nacional, foi preciso excluir das análises as entregas com nota de empenho emitida nesse período. A razão para isso é que a maioria dos empenhos realizados nesse mês somente é enviada para os fornecedores no próximo ano, portanto, o cálculo do "Prazo de entrega" seria superestimado pelos empenhos realizados em novembro.

Com relação às variáveis explicativas, os dados demonstram um número limitado de fornecedores na disputa. Em média, foram 5,8 concorrentes por lote, e 37,7\% dos lotes foram disputados por no máximo três fornecedores, que é número mínimo de competidores indicados para realização de uma contratação eletrônica (Yukins e Wallace Jr., 2005). Quanto às capacidades acumuladas, nota-se que os fornecedores possuem, em média, mais de 11 anos de atuação no mercado e estão a cerca de seis anos cadastrados no Sicaf. No que se refere à reputação, verifica-se que, em média, cada empresa contratada possui ao menos uma sanção por desempenho insatisfatório em transações anteriores com a organização pesquisada, e 43,6\% das empresas contratadas já foram sancionadas ao menos uma vez pela organização contratante.

A tabela 2, a seguir, apresenta os resultados das regressões estimadas. Foram estimados dois modelos por MQO ( 1 e 5) e seis modelos por regressão quantílica ( 2 a 4 e 6 a 8 ). Os modelos 1 a 4 permitem a identificação dos fatores associados à redução nos preços licitados, enquanto os modelos 5 a 8 permitem verificar os fatores associados à redução dos prazos de entrega, bem como se existe uma associação significativa entre a economia obtida na fase de licitação e os prazos de entrega.

\section{TABELA 2 FATORES DETERMINANTES DO DESEMPENHO DAS LICITAÇÕES ELETRÔNICAS}

\begin{tabular}{|c|c|c|c|c|c|c|c|c|}
\hline & \multirow{2}{*}{$\begin{array}{l}\text { MQO } \\
\text { (1) }\end{array}$} & \multicolumn{3}{|c|}{ Quantílica } & \multirow{2}{*}{$\begin{array}{l}\text { MQO } \\
\text { (5) }\end{array}$} & \multicolumn{3}{|c|}{ Quantílica } \\
\hline & & (2) q25 & (3) q50 & (4) q75 & & (6) q25 & (7) q50 & (8) q75 \\
\hline \multicolumn{9}{|l|}{ Ambiente Competitivo } \\
\hline Redução nos preços & & & & & $\begin{array}{l}0,009 \\
(0,040)\end{array}$ & $\begin{array}{l}0,004 \\
(0,016)\end{array}$ & $\begin{array}{l}0,006 \\
(0,025)\end{array}$ & $\begin{array}{l}0,010 \\
(0,035)\end{array}$ \\
\hline Fornecedores & $\begin{array}{l}2,488^{\star \star \star} \\
(0,140)\end{array}$ & $\begin{array}{l}1,920^{\star \star \star} \\
(0,113)\end{array}$ & $\begin{array}{l}3,192^{\star \star \star} \\
(0,142)\end{array}$ & $\begin{array}{l}3,761^{\star \star \star} \\
(0,238)\end{array}$ & $\begin{array}{l}-0,566^{\star \star} \\
(0,262)\end{array}$ & $\begin{array}{l}-0,187 \\
(0,203)\end{array}$ & $\begin{array}{l}-0,098 \\
(0,259)\end{array}$ & $\begin{array}{l}-0,107 \\
(0,312)\end{array}$ \\
\hline \multicolumn{9}{|l|}{ Competência Acumulada } \\
\hline Experiência de mercado (anos) & $\begin{array}{l}0,114^{\star *} \\
(0,057)\end{array}$ & $\begin{array}{l}0,054 \\
(0,036)\end{array}$ & $\begin{array}{l}0,143^{\star *} \\
(0,068)\end{array}$ & $\begin{array}{l}0,135 \\
(0,117)\end{array}$ & $\begin{array}{l}0,013 \\
(0,124)\end{array}$ & $\begin{array}{l}0,035 \\
(0,284)\end{array}$ & $\begin{array}{l}0,098 \\
(0,120)\end{array}$ & $\begin{array}{l}0,220 \\
(0,232)\end{array}$ \\
\hline Experiência no setor público (anos) & $\begin{array}{l}0,051 \\
(0,127)\end{array}$ & $\begin{array}{l}-0,059 \\
(0,079)\end{array}$ & $\begin{array}{l}-0,198 \\
(0,163)\end{array}$ & $\begin{array}{l}0,059 \\
(0,211)\end{array}$ & $\begin{array}{l}-0,321 \\
(0,342)\end{array}$ & $\begin{array}{l}0,375 \\
(0,536)\end{array}$ & $\begin{array}{l}0,043 \\
(0,377)\end{array}$ & $\begin{array}{r}-0,443 \\
(0,637)\end{array}$ \\
\hline \multicolumn{9}{|l|}{ Reputação } \\
\hline Histórico de sanção & $\begin{array}{l}-1,079^{\star \star \star} \\
(0,236)\end{array}$ & $\begin{array}{l}-0,017 \\
(0,089)\end{array}$ & $\begin{array}{l}-0,657^{\star \star} \\
(0,311)\end{array}$ & $\begin{array}{l}-1,661^{\star \star \star} \\
(0,423)\end{array}$ & $\begin{array}{l}3,003^{\star \star \star} \\
(0,570)\end{array}$ & $\begin{array}{l}2,851^{\star \star \star} \\
(0,752)\end{array}$ & $\begin{array}{l}3,597^{\star \star \star} \\
(0,560)\end{array}$ & $\begin{array}{l}4,332^{\star \star \star} \\
(0,939)\end{array}$ \\
\hline
\end{tabular}




\begin{tabular}{|c|c|c|c|c|c|c|c|c|}
\hline & \multirow{2}{*}{$\begin{array}{l}\text { MQO } \\
\text { (1) }\end{array}$} & \multicolumn{3}{|c|}{ Quantílica } & \multirow{2}{*}{$\begin{array}{c}\text { MQO } \\
\text { (5) }\end{array}$} & \multicolumn{3}{|c|}{ Quantílica } \\
\hline & & (2) q25 & (3) $q 50$ & (4) q75 & & (6) q25 & (7) q50 & (8) q75 \\
\hline \multicolumn{9}{|l|}{ Controles } \\
\hline \multirow[t]{2}{*}{ MPE } & $-4,601^{\star \star \star}$ & $-0,820$ & $-5,301^{\star \star \star}$ & $-4,382^{\star \star}$ & $9,779^{\star \star \star}$ & $12,635^{\star \star \star}$ & $14,104^{\star \star \star}$ & $15,172^{\star \star \star}$ \\
\hline & $(1,237)$ & $(0,819)$ & $(1,762)$ & $(2,003)$ & $(2,308)$ & $(4,421)$ & $(3,400)$ & $(2,756)$ \\
\hline \multirow[t]{2}{*}{ Log Distância (km) } & 0,403 & $0,254^{*}$ & $0,447^{*}$ & 0,321 & $3,031^{\star \star \star}$ & $3,191^{\star \star}$ & 1,432 & 2,115 \\
\hline & $(0,248)$ & $(0,148)$ & $(0,244)$ & $(0,457)$ & $(0,773)$ & $(1,331)$ & $(1,447)$ & $(1,594)$ \\
\hline \multirow[t]{2}{*}{ Log Valor estimado (R\$) } & 0,150 & $-0,003$ & $-0,207$ & 0,761 & 0,301 & $-0,286$ & $-0,016$ & 0,150 \\
\hline & $(0,272)$ & $(0,058)$ & $(0,191)$ & $(0,482)$ & $(0,647)$ & $(0,498)$ & $(0,505)$ & $(0,685)$ \\
\hline \multicolumn{9}{|l|}{ Tipos de material } \\
\hline \multicolumn{9}{|l|}{ Expediente - baseline } \\
\hline \multirow[t]{2}{*}{ Limpeza e higienização } & $-3,515^{\star \star}$ & $-2,822^{\star \star \star}$ & $-1,522$ & $-2,003$ & 2,610 & 2,582 & $-4,403$ & 2,610 \\
\hline & $(1,707)$ & $(1,078)$ & $(1,878)$ & $(3,163)$ & $(4,128)$ & $(6,778)$ & $(6,396)$ & $(4,128)$ \\
\hline \multirow[t]{2}{*}{ Gênero alimentício } & $3,998^{\star \star \star}$ & $3,899^{\star \star \star}$ & $3,314^{\star \star \star}$ & 4,079 & $-0,119$ & 2,240 & $-5,517$ & $-0,119$ \\
\hline & $(1,358)$ & $(0,771)$ & $(1,077)$ & $(2,659)$ & $(4,441)$ & $(8,046)$ & $(8,517)$ & $(4,441)$ \\
\hline \multirow[t]{2}{*}{ Copa e cozinha } & $-6,535^{\star \star \star}$ & $-4,106^{\star \star}$ & $-5,099^{\star \star}$ & $-4,526$ & 1,570 & 3,068 & $-7,813$ & $-15,006$ \\
\hline & $(2,008)$ & $(1,648)$ & $(2,104)$ & $(5,160)$ & $(4,907)$ & $(8,036)$ & $(6,826)$ & $(9,930)$ \\
\hline \multirow[t]{2}{*}{ Proteção e segurança } & 1,015 & $2,835^{\star \star \star}$ & 2,683 & 3,612 & $4,906^{\star}$ & $10,410^{\star \star}$ & 4,292 & $-2,347$ \\
\hline & $(1,790)$ & $(0,920)$ & $(2,135)$ & $(3,482)$ & $(2,883)$ & $(5,107)$ & $(3,837)$ & $(4,613)$ \\
\hline \multirow[t]{2}{*}{ Elétrico } & 0,631 & 0,969 & $3,716^{\star}$ & $-3,472$ & $11,445^{\star \star \star}$ & 9,105 & $18,024^{\star * \star}$ & 6,364 \\
\hline & $(2,011)$ & $(2,485)$ & $(2,241)$ & $(3,188)$ & $(3,191)$ & $(7,602)$ & $(6,730)$ & $(4,491)$ \\
\hline \multirow[t]{2}{*}{ Outros } & $6,813^{\star \star \star}$ & $3,297^{\star \star \star}$ & $7,850^{\star \star \star}$ & $12,568^{\star \star \star}$ & 3,273 & $7,167^{\star}$ & 5,232 & $-2,509$ \\
\hline & $(1,260)$ & $(0,802)$ & $(1,543)$ & $(1,869)$ & $(3,158)$ & $(4,008)$ & $(3,937)$ & $(3,884)$ \\
\hline \multirow[t]{2}{*}{ Constante } & 4,314 & $-7,970^{\star \star \star}$ & $-2,292$ & 0,015 & 4,926 & $-9,594$ & 6,218 & 11,718 \\
\hline & $(3,096)$ & $(1,737)$ & $(3,405)$ & $(4,424)$ & $(6,274)$ & $(7,516)$ & $(8,490)$ & $(7,962)$ \\
\hline N & 3.318 & 3.318 & 3.318 & 3.318 & 283 & 283 & 283 & 283 \\
\hline F Test & $66,80^{\star \star \star}$ & & & & $7,98^{\star \star \star}$ & & & \\
\hline R2/Pseudo R2 & 0,241 & 0,117 & 0,218 & 0,175 & 0,248 & 0,247 & 0,236 & 0,249 \\
\hline
\end{tabular}

Notas: Erros-padrão robustos entre parênteses ${ }^{* *} \mathrm{p}<0,01,{ }^{* *} \mathrm{p}<0,05,{ }^{*} \mathrm{p}<0,1$.

Fonte: Resultados da pesquisa.

\subsection{EFEITOS DO AMBIENTE COMPETITIVO}

Conforme pode ser observado, no modelo 1, um aumento no número de fornecedores tem um efeito positivo, em média, de 2,4\% na economia alcançada. Igualmente, nos modelos 2,3 e 4, verifica-se que a regressão quantílica permitiu uma análise mais detalhada quanto aos efeitos do número de fornecedores sobre os preços contratados, na medida em que os resultados revelam coeficientes crescentes e significativos em todos os quartis. Esses resultados vão ao encontro da primeira hipótese da pesquisa e corroboram os estudos anteriores realizados por autores como Croom e Brandon-Jones (2007) e Reis e Cabral (2015), os quais defendem a redução de barreiras à entrada e o aumento do número de concorrentes como uma estratégia capaz de promover melhorias na economia para os cofres públicos. 
Em relação aos efeitos da economia obtida na fase de licitação sobre os prazos de entrega, os resultados apresentados nos modelos 5, 6, 7 e 8 indicaram que a "Redução nos preços" não apresenta efeitos significativos sobre a celeridade na entrega. Esses resultados não corroboram a segunda hipótese do estudo. Contudo, vale ressaltar que tal resultado não significa que o acirramento da competição e a redução nos preços licitados não sejam um problema potencial para o desempenho ex post das aquisições públicas eletrônicas, quando se reconhece que as decisões logísticas estão sujeitas aos trade-offs que incluem custo; qualidade; velocidade; externalidades positivas ou negativas (Vaz e Lotta, 2011). Assim, é possível que os problemas decorrentes de propostas muito baixas e de comportamentos oportunistas por parte dos fornecedores atuem em outras dimensões de desempenho, como desvios na qualidade do objeto ou nas especificações contratadas e, até mesmo, em termos de desistência do contrato, de modo que não estejam relacionados com a proxy de desempenho adotada neste estudo.

Além disso, é provável que muitos gestores públicos não estejam aparelhados com conhecimentos técnicos e recursos suficientes para monitorar e fiscalizar o desempenho ex post das aquisições, particularmente das compras eletrônicas devido ao volume e à diversidade de itens envolvidos nesse tipo de contratação. De forma ilustrativa, talvez, as restrições observadas na fase de levantamento de dados sobre a data de recebimento das aquisições realizadas pela organização pesquisada sejam uma evidência dos problemas enfrentados pela organização contratante para controlar e fiscalizar suas compras. Aproveitando-se dessas limitações, os fornecedores podem agir de forma oportunista, ofertando produtos de menor qualidade ou, até mesmo, com especificações diferentes das estabelecidas no edital, prejudicando assim o desempenho das compras públicas, conforme apontado por Ba e Pavlou (2002) e Faria e colaboradores (2010a). Logo, os resultados aqui apresentados reforçam a necessidade de pesquisas mais aprofundadas, que investiguem, empiricamente, os fatores determinantes do desempenho das aquisições públicas nas suas múltiplas dimensões.

\subsection{EFEITOS DAS CAPACIDADES ACUMULADAS}

Quanto ao efeito das capacidades acumuladas, o resultado obtido no modelo por MQO demonstra que, em média, quanto maior a experiência da empresa no mercado, maior sua capacidade para promover reduções nos preços ofertados $(\mathrm{p}<0,05)$. Na regressão quantílica, por sua vez, verifica-se que a experiência de mercado somente é significativa no segundo quartil (q50). Com efeito, diante da heterogeneidade dos dados, o emprego da regressão quantílica permitiu uma análise mais robusta e detalhada, que não poderia ser observada na regressão por MQO. Dessa forma, a terceira hipótese do estudo, que assinala a importância das experiências acumuladas pelos fornecedores para melhoria dos preços praticados, é corroborada apenas no modelo por MQO e no quartil (q50).

Em relação à ausência de efeito no quartil superior, pode-se supor que fornecedores mais experientes sejam menos propensos a se envolver em disputas com lances agressivamente mais baixos, o que induziria a elevadas reduções nos preços registrados. Igualmente, para o quartil inferior, uma explicação anedótica seria que a menor economia alcançada no processo de contratação decorre de uma definição equivocada na fase de planejamento sobre o valor estimado para o objeto licitado, 
mais precisamente, esse equívoco seria uma subprecificação do lote. Assim, seria provável que os fornecedores com maior experiência não participassem de uma licitação em que o preço estimado esteja subavaliado, não aceitando um lucro menor do que aquele que poderiam obter em uma licitação alternativa (Tadelis, 2012).

Em termos de prazos de entrega, embora a hipótese proposta estabelecesse uma relação positiva entre as experiências acumuladas pelo fornecedor e a celeridade na entrega, aparentemente, o tempo de atuação no mercado e no setor público da contratada não parece influenciar a velocidade da entrega. Logo, os resultados obtidos não corroboram a quarta hipótese do estudo.

\subsection{EFEITOS DA REPUTAÇÃO}

Quanto aos efeitos da reputação, os resultados reportados nos modelos 1, 3 e 4 mostram uma associação negativa entre o histórico de sanção por desempenho insatisfatório da contratada e a economia obtida no certame. Nos modelos 5 a 8 também se verifica que os fornecedores com histórico de baixo desempenho estão associados a prazos de entrega mais longos $(\mathrm{p}<0,01)$. Esses resultados demonstram que mecanismos de incentivos baseados em reputação, comumente utilizados em plataformas online de compras privadas (Ba e Pavlou, 2002; Spagnolo, 2012), não parecem ser eficazes no contexto brasileiro. Isso porque a proxy de reputação utilizada demonstra que os fornecedores com sanções em contratações anteriores são justamente aqueles que tornam o prazo de entrega mais demorado, o que corrobora a quinta hipótese do estudo.

Estes resultados têm, pelo menos, duas interpretações possíveis. Em primeiro lugar, a partir das experiências acumuladas ao longo do tempo em que atuam como fornecedores de organizações públicas, essas empresas com histórico de sanções podem ter identificado que as punições por atrasos não sejam prováveis, particularmente, nas aquisições de objetos de menor complexidade e de consumo frequente. Em segundo lugar, esses mesmos fornecedores provavelmente perceberam que os custos impostos pelas sanções normalmente aplicadas podem ser inferiores aos ganhos obtidos com o protelamento da entrega. Destarte, os fornecedores teriam pouco incentivo para garantir a celeridade da entrega.

No que concerne aos baixos custos supostamente associados às sanções, é importante observar que, diferentemente do que ocorre em outras plataformas online de contratação, como eBay e Freelancer.com, nas licitações públicas brasileiras os registros relativos ao histórico de desempenho não são utilizados como critério para pré-qualificação dos fornecedores ou para o ranqueamento dos mesmos em aquisições futuras. Assim, diante da baixa expectativa de ganhos posteriores em decorrência de uma reputação confiável, as sanções contratuais previstas nos editais das licitações públicas eletrônicas têm se mostrado incapazes de direcionar o comportamento dos fornecedores. Porém, em que pese os resultados apontados neste e em outros estudos, como o de Spagnolo (2012), os legisladores responsáveis pela formulação e reforma dos regulamentos de compras públicas ainda são reticentes quanto às implicações dos mecanismos de governança baseados em reputação sobre as taxas de entrada em licitações públicas, sobre o tratamento isonômico dos fornecedores, bem como sobre a necessidade de evitar o favoritismo e a corrupção nos processos licitatórios.

O quadro 1 apresenta um resumo dos principais resultados obtidos para cada uma das hipóteses lançadas no estudo. 


\section{QUADRO 1 RESUMO DOS RESULTADOS}

\begin{tabular}{ll}
\multicolumn{1}{c}{ Hipóteses } & Resultados \\
H1: Quanto maior o número de concorrentes nas licitações públicas & Corroborada \\
eletrônicas, maior a economia nos preços praticados. & \\
H2: Quanto maior a economia obtida na licitação eletrônica, maior & Não corroborada \\
a dilatação no prazo de entrega do objeto contratado. & \\
H3: Quanto maior a competência acumulada pela empresa & Corroborada apenas nos modelos 1 (MQ0) e 3 (q50) \\
contratada, maior a economia nos preços praticados. & \\
H4: Quanto maior a competência acumulada pela empresa & Não corroborada \\
contratada, menor o prazo de entrega do objeto contratado. & \\
H5: Quanto maior o histórico de desempenho insatisfatório de um & Corroborada \\
fornecedor, maior o prazo de entrega do objeto contratado. &
\end{tabular}

Fonte: Resultados da pesquisa.

\section{CONSIDERAÇÕES FINAIS}

\subsection{IMPLICAÇÕES PRÁTICAS E TEÓRICAS}

Sob o ponto de vista prático, os achados da pesquisa abrem espaço para uma discussão mais aprofundada acerca do comportamento das empresas contratadas nas licitações eletrônicas e sobre o uso de novos mecanismos de governança que estimulem a construção de uma reputação confiável por parte dos fornecedores. Para os gestores de compras públicas, o efeito positivo do número de fornecedores sobre o preço licitado reforça a importância dos investimentos em mecanismos de contratação, como as plataformas eletrônicas de compras, que ampliam a publicidade dos editais de licitações e diminuem as barreiras à entrada de novos participantes.

Para os formuladores de políticas públicas e os órgãos responsáveis por planejar, supervisionar e orientar normativamente as compras governamentais, por sua vez, o estudo contribui ao demonstrar a necessidade de explorar o potencial das plataformas online de compras para a melhoria das atividades de monitoramento e controle na fase de execução e avaliação da aquisição. Tal estratégia contribuiria para dirimir a escassez de informações sobre outras medidas de desempenho e a dificuldade encontrada para acessar as medidas já existentes, ampliando a análise para as demais fases da cadeia de suprimento.

Paralelamente, o estudo põe em evidência a importância da elaboração de manuais de boas práticas para formulação de editais ou padronização de produtos, dado que 11,6\% dos lotes licitados não foram contratados, em função da ausência de fornecedores interessados na contratação ou da ocorrência de preços acima dos valores estimados. Ademais, a definição dessas boas práticas poderia reduzir os casos em que a economia obtida atingiu níveis que transcendem a razoabilidade, como reduções nos preços licitados superiores a $90 \%(\mathrm{n}=31)$. 
Do ponto de vista teórico, ao discorrer sobre os fatores determinantes para os resultados compras públicas em distintas dimensões de desempenho e ao realizar uma análise sobre os trade-offentre custos e outras medidas de qualidade, o artigo contribui com pesquisas anteriores no campo das compras públicas (Tassabehji et al., 2006; Tridapalli, Fernandes e Machado, 2011; Vaz e Lotta, 2011; Freitas e Maldonado, 2013). Ademais, ao trazer evidências empíricas robustas sobre o papel da reputação dos fornecedores sobre as dimensões de desempenho em compras públicas, o trabalho contribui para o debate teórico acerca da importância dos mecanismos de governança nos procedimentos de compras públicas (Spagnolo, 2012) e de fatores ligados a competências acumuladas em relações entre empresas e governo (Cabral, 2017).

\subsection{LIMITAÇÕES DO ESTUDO}

Evidentemente, apesar dos esforços empreendidos, é preciso mencionar que o estudo apresenta uma série de limitações. Em primeiro lugar, ressalta-se que a pesquisa é circunscrita a uma única organização e adota uma análise empírica essencialmente descritiva, fornecendo apenas evidências de uma associação entre variáveis e não causalidade. Assim, as advertências habituais quanto à possibilidade de generalização e validade externa desta pesquisa devem ser observadas. Em segundo, os fatores impeditivos encontrados na fase de coleta de dados e a falta de registros sobre algumas medidas de desempenho importantes impediram a inclusão de outros trade-offs logísticos nas análises empreendidas, como custos versus qualidade (especificada e/ou percebida) e custos versus conformidade, bem como a ampliação da base de dados com a inclusão de informações de outros órgãos da administração federal. Em terceiro, vale destacar que o foco sobre as aquisições de materiais de consumo pode ser uma possível explicação para a ausência de um efeito negativo da economia obtida na fase de licitação sobre o desempenho ex post da aquisição, uma vez que os efeitos das reduções nos preços ocorridas na fase de licitação possam ser mais expressivos em contratos de serviços. Notadamente, embora diversos tipos de serviços contratados mediante licitações eletrônicas sejam considerados comuns, ou seja, de baixa especificidade, eles estão sujeitos a incertezas que podem não ser observadas nas compras de materiais de consumo. Diante dessas limitações, fica evidente que fontes de dados adicionais são importantes. Contudo, acredita-se que o presente trabalho constitui um passo importante para a consolidação de linhas de pesquisa voltadas para a execução de análises robustas sobre os determinantes de desempenho em licitações eletrônicas. 


\section{REFERÊNCIAS}

BA, Sulin; PAVLOU, Paul A. Evidence of the effect of trust building technology in electronic markets: price premiums and buyer behavior. MIS Quarterly, v. 26, n. 3, p. 243-268, 2002.

BAJARI, Patrick; MCMILLAN, Robert; TADELIS, Steven. Auctions versus negotiations in procurement: an empirical analysis. Journal of Law, Economics, and Organization, v. 25, n. 2, p. 372-399, 2009.

BARNEY, Jay. Firm resources and sustained competitive advantage. Journal of Management, v. 17, n. 1, p. 99-120, 1991.

BARNEY, Jay. How a firm's capabilities affect boundary decisions. MIT Sloan Management Review, v. 40, n. 3, p. 137-145, 1999.

BARNEY, Jay; HANSEN, Mark H. Trustworthiness as a source of competitive advantage. Strategic Management Journal, v. 15, n. S1, p. 175-190, 1994.

BRANDON-JONES, Alistair; CAREY, Sinéad. The impact of user-perceived e-procurement quality on system and contract compliance. International Journal of Operations \& Production Management, v. 31, n. 3, p. 274-296, 2011.

BRASIL. Informações gerenciais de contratações e compras públicas. 2015. Disponível em: <www. comprasgovernamentais.gov.br/arquivos/estatisticas/01-apresentacao-siasg-dados-gerais-_2014.pdf>. Acesso: 15 jul. 2015.

BRETSCHNEIDER, Stuart; MARC-AURELE JR., Frederick; WU, Jiannan. "Best practices" research: a methodological guide for the perplexed. Journal of Public Administration Research and Theory, v. 15, n. 2, p. 307-323, 2005.

BOYNE, George A.; WALKER, Richard M. Strategic management and public service performance: the way ahead. Public Administration Review, v. 70, n. 1, p. 185-192, 2010.

BULOW, Jeremy; KLEMPERER, Paul. Auctions versus negotiations. The American Economic Review, v. 86, n. 1, p. 180-194, 1996.

CABRAL, Sandro. Reconciling conflicting policy objectives in public contracting: the enabling role of capabilities. Journal of Management Studies, v. 54, n. 6, p. 823-853, 2017.
CANIËLS, Marjolein C. J.; VAN RAAIJ, Erik M. Do all suppliers dislike electronic reverse auctions? Journal of Purchasing and Supply Management, v. 15, n. 1, p. 12-23, 2009.

CROOM, Simon; BRANDON-JONES, Alistair. Impact of e-procurement: experiences from implementation in the UK public sector. Journal of Purchasing and Supply Management, v. 13, n. 4, p. 294-303, 2007.

DOHERTY, Neil F.; MCCONNELL, Danny J.; ELLIS-CHADWICK, Fiona. Institutional responses to electronic procurement in the public sector. International Journal of Public Sector Management, v. 26, n. 6, p. 495-515, 2013.

EISENHARDT, Kathleen M.; MARTIN, Jeffrey A. Dynamic capabilities: what are they? Strategic Management Journal, v. 21, n. 10-11, p. 1105-1121, 2000.

FARIA, Evandro R. et al. Aspectos transacionais e comportamentais dos agentes no pregão eletrônico: um enfoque na administração pública. Revista de Economia e Administração, v. 9, n. 2, p. 151-169, 2010a.

FARIA, Evandro R. et al. Fatores determinantes da variação dos preços dos produtos contratados por pregão eletrônico. Rev. Adm. Pública, Rio de Janeiro, v. 44, n. 6, p. 1405-1428, nov./dez. 2010b.

FERNANDES, Ciro C. C. Abrangência, inserção e impacto transformador dos sistemas de compras eletrônicas na administração pública - análise do Siasg/Comprasnet. Revista do Serviço Público, v. 56, n. 2, p. 195-216, 2005.

FREITAS, Marcelo; MALDONADO, José M. S. V. O pregão eletrônico e as contratações de serviços contínuos. Rev. Adm. Pública, Rio de Janeiro, v. 47, n. 5, p. 1265-1281, set./out. 2013.

GILL, John; FRAME, Philip. Managing financial stringency in the public sector. Public Administration, v. 68, n. 4, p. 517-537, 1990.

HART, Oliver; SHLEIFER, Andrei; VISHNY, Robert $\mathrm{W}$. The proper scope of government: theory and an application to prisons. The Quarterly Journal of Economics, v. 112, n. 4, p. 1127-1161, 1997.

JAP, Sandy D. Online reverse auctions: issues, themes, and prospects for the future. Journal of the Academy of Marketing Science, v. 30, n. 4, p. 506-525, 2002.

JAP, Sandy D. The impact of online reverse auction design on buyer-supplier relationships. Journal of Marketing, v. 71, n. 1, p. 146-159, 2007. 
KELMAN, Steven. Remaking federal procurement. Public Contract Law Journal, v. 31, n. 4, p. 581-622, 2002.

MENEZES, Ronald A.; SILVA, Renaud B.; LINHARES, Alexandre. Leilões eletrônicos reversos multiatributo: uma abordagem de decisão multicritério aplicada às compras públicas brasileiras. Revista de Administração Contemporânea, v. 11, n. 3, p. 11-33, 2007.

MOON, Jae M. E-procurement management in state governments: diffusion of e-procurement practices and its determinants. Journal of Public Procurement, v. 5, n. 1, p. 54-72, 2005.

MOON, Jae M. The evolution of e-government among municipalities: rhetoric or reality? Public Administration Review, v. 62, n. 4, p. 424-433, 2002.

PIENING, Erk P. Dynamic capabilities in public organizations: a literature review and research agenda. Public Management Review, v. 15, n. 2, p. 209-245, 2013.

REIS, Paulo R. C.; CABRAL, Sandro. Public procurement strategy: the impacts of a preference programme for small and micro businesses. Public Money \& Management, v. 35, n. 2, p. 103-110, 2015.

SPAGNOLO, Giancarlo. Reputation, competition, and entry in procurement. International Journal of Industrial Organization, v. 30, n. 3, p. 291-296, 2012.

STANDIFIRD, Stephen S. Reputation and e-commerce: eBay auctions and the asymmetrical impact of positive and negative ratings. Journal of Management, v. 27, n. 3, p. 279-295, 2001.

TADELIS, Steven. Public procurement design: lessons from the private sector. International Journal of Industrial Organization, v. 30, n. 3, p. 297-302, 2012.
TASSABEHJI, Rana et al. Reverse e-auctions and supplier-buyer relationships: an exploratory study. International Journal of Operations \& Production Management, v. 26, n. 2, p. 166-184, 2006.

TEECE, David J.; PISANO, Gary; SHUEN, Amy. Dynamic capabilities and strategic management. Strategic Management Journal, v. 18, n. 7, p. 509-533, 1997.

TRIDAPALLI, Juarez P.; FERNANDES, Elton; MACHADO, Waltair V. Gestão da cadeia de suprimento do setor público: uma alternativa para controle de gastos correntes no Brasil. Rev. Adm. Pública, Rio de Janeiro, v. 45, n. 2, p. 401-433, mar./abr. 2011.

\section{UNITED NATIONS PUBLIC ADMINISTRATION} NETWORK. E-procurement: towards transparency and efficiency in public service delivery report of the expert group meeting. 2011. Disponível em: <http:// unpan1.un.org/intradoc/groups/public/documents/ un/unpan047627.pdf>. Acesso em: 23 jul. 2014.

VAZ, José C.; LOTTA, Gabriela S. A contribuição da logística integrada às decisões de gestão das políticas públicas no Brasil. Rev. Adm. Pública, Rio de Janeiro, v. 45, n. 1, p. 107-139, jan./fev. 2011.

WINTER, Sidney G. Understanding dynamic capabilities. Strategic Management Journal, v. 24, n. 10, p. 991-995, 2003.

WOOLDRIDGE, Jeffrey M. Introdução à econometria: uma abordagem moderna. São Paulo: Pioneira Thomson Learning, 2006.

YUKINS, Christopher R.; WALLACE JR., Don. Uncitral considers electronic reverse auctions, as comparative public procurement comes of age in the US. Public Procurement Law Review, 2005. Disponível em: <http://papers.ssrn.com/soL3/papers. cfm?abstract_id=711847>. Acesso em: 5 maio 2015.

\section{Paulo Ricardo da Costa Reis}

Doutor em administração pelo Núcleo de Pós-graduação em Administração da UFBA, professor adjunto do Programa de Graduação em Gestão Pública para o Desenvolvimento Econômico e Social do Instituto de Pesquisa e Planejamento Urbano e Regional da UFRJ e professor permanente do Programa de PósGraduação em Gestão e Estratégia da UFRRJ. E-mail: pauloreis@ippur.ufrj.br.

\section{Sandro Cabral}

Doutor em administração, professor associado do Insper Instituto de Ensino e Pesquisa e professor adjunto (licenciado) da Escola de Administração da UFBA. E-mail: sandroc2@insper.edu.br. 